\title{
AN ACTIVE ROLE FOR THE ELDERLY IN THE PROCESS FOR AN INTEGRATED EUROPE
}

\author{
REMEDIOS LÓPEZ-LIRIA
}

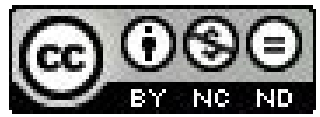

Faculty of Health Science, University of Almería, La Cañada de San Urbano, 04120 Almería (Spain)

\section{PILAR DÍAZ-LÓPEZ}

Faculty of Health Science, University of Almería, La Cañada de San Urbano, 04120 Almería (Spain)

\section{PATRICIA ROCAMORA-PÉREZ}

Faculty of Health Science, University of Almería, La Cañada de San Urbano, 04120 Almería (Spain)

\section{JOSÉ M. AgUILAR-PARRA, ANA MANZANO-LEÓN}

Faculty of Health Science, University of Almería, La Cañada de San Urbano, 04120 Almería (Spain)

\section{DAVID PADILLA-GÓNGORA}

Faculty of Health Science, University of Almería, La Cañada de San Urbano, 04120 Almería (Spain)

\section{E-mail address: liriareme@ual.es}

\begin{abstract}
The European project entitled "Integrating adults and the elderly towards a Europe of knowledge", coordinated by the University of Almería, within the actions of "Grundtvig learning partnerships for adult education", has carried out the assessment of an educational program for over 55 years in five countries. The aim of the learning partnership was "to encourage the development of innovative practices in education of older people and their transfer between countries".

Methods: Some of the following teaching tools and methods were used to promote intercultural communication skills: simulation activities, followed by reflective discussion and/or written analysis; guided group activities; local visits to contact people from other countries; ethnographic projects.
\end{abstract}


Results: The courses provide knowledge and understanding of culture, institutions and different ways of life in diverse communities, and encourage reflection about their own cultural behaviour, practices and attitudes, as well as those of others. Old people enhance communication in their community by means of meetings, in which they talk about their common concerns. This can help the elderly to overcome problems and reduce feelings of loneliness. The courses also help old people acquire new knowledge and skills in a rapidly changing world.

Conclusions: Participants' motivation increased as the sessions were developed, since the contents of the classes agreed with their own interests, with a constant widening of knowledge. Everybody had an active role in the discussions. This training revises some beliefs about ageing, such as the removal of the image of the idle retired person; at the same time, it promotes active retirement, intergenerational relationships and independence, and improves social and personal skills.

Key words: lifelong learning, elderly, intercultural

\section{INTRODUCTION}

The elderly population is growing at record rates in Europe (United Nations, Department of Economic and Social Affairs, 2013). The technical and medical advances have permitted the increase of life expectancy in all European countries (Garssen, 2006). As a consequence of this increase of life expectancy, retired elderly people have more free time (Montero García \& Bedmar Moreno, 2010).

Retirement can have negative consequences, such as reduction of income or loss of social relations, which can produce loneliness and isolation; on the other hand, another consequence of retirement is an increase of free time that allows the person to do activities and to aim for old-new goals which were just infeasible before retirement (Núbia Alvarenga, Kiyan, Bitencourt, \& da Silva Wanderley, 2009). Thus, it is necessary to have a defined plan of life for this stage, which allows the elderly to live their lives positively and convert potentially negative situations into positive ones. Also their life experiences with their psychological and social aspects can be lived as a reward and can enrich themselves and those around them. It is certain that leisure and free time activities can be conditioned by the income of the person, which reduces as they get older, and by the environment where they live, but it is always possible to do some activities according to each individual's needs, health condition, education or acquired habits (Padilla, Durand, López-Liria, \& Amarante, 2013). Therefore it is essential that mature people know how to plan their free time, and to adapt the different activities to their own characteristics and to each specific situation.

\section{SOCIAL RELATIONSHIPS}

Good social relationships at any stage of life are a central element of social integration, and welfare of men and women is determined by good social

relations (Diener, \& Suh, 2000). Studies with the elderly have shown that the 
quality rather than the quantity of social relations increases well-being (Helliwell, \& Putnam, 2004). The existence of at least one confidant is very important in adulthood. In addition, positive social relationships are a fundamental resource for social support, for example, when adults are in need of care or help. At the same time, a good social network that provides both emotional and instrumental support, affects both health and the success of socio-medical interventions positively, as social support in addition to its direct effects may also show indirect influence on the sense of a "buffering effect" (Dolan, Peasgood, \& White, 2008).

The condition for social competence is self-competence (Gagné, \& Deci 2005): to identify one's own values and motivations; to recognise our ability to use them purposefully; to know our weaknesses and to accept and reduce them; to save our energy.

Only the correct perception of one's skills and deficiencies will enable the development and implementation of competent guide behaviour (also called skills) in social situations. Examples of relevant skills are the ability to say no; to express wants and needs; to make contacts, to start and end conversations; to openly express positive or negative emotions.

\section{HEALTH STATUS}

Considerable research has shown that old adults vary tremendously in their health status and the problems they suffer. As people grow old, acute medical conditions become less frequent while chronic conditions become more prevalent (SAMHSA, 2000). Physical diseases in the elderly may be more difficult to detect, as signs and symptoms may be diminished or absent, delayed in onset or not characteristic of the same disease in a younger person (Nolte, \& McKee, 2008).

Above all, it is important to keep in mind that the elderly can do something about their health in old age. For example, a small change in lifestyle, such as exercising more or quitting smoking, may lead to a significant change in health status. Among the preventive measures recommended for the elderly we find physical exercise, although the health concept is multidimensional and includes the biological, psychological and social areas (López-Liria, PadillaGóngora, Catalan-Matamoros, Rocamora-Pérez, Pérez-de la Cruz, \& Fernández-Sánchez, 2015). The statement 'an organ not in use gets atrophied' can be also extrapolated to both the psychological and mental aspects. Lack of use in cognitive terms is responsible for learning disability in old age, that is the relevance of training and stimulation to activate and boost mental energy.

\section{MODERN TECHNOLOGY TOOLS}

The potential of information technology means a great tool for older people to improve their quality of life. However, the elderly are among the lowest 
user rates in both the use of computers and the Internet (File, \& Ryan, 2014). It is necessary to promote technological literacy of our elders in order to promote their active social life, including family, friends, leisure activities, and even their own health care. The Internet is a vast source of information, and it offers more possibilities for relationships, so teaching the elderly to use this resource can positively affect their lives.

Nowadays, personal computers are all around us, and they are essential in our work. Age is not an impediment to approach computers to meet personal needs. Quite the contrary, studies show the great benefits of computing for older people in the neurological aspects, both emotional and relational (Zelinski, \& Reyes, 2009).

The psycho-activation through the computer is a set of exogenous actions capable of enhancing endogenous capacity of the individual to stimulate their psychic dynamics. Computing is the great unfinished business in the elderly, with huge difficulties in the use and management of computers. Moreover, a large number of current elderly people have only a basic or medium educational level, with no previous contact with computer technology. They still find it difficult to access, due to the high costs of the ultimate technology (Independent Age, 2008).

\section{LEISURE AND FREE TIME}

After retirement, free time is the most important value of the elderly. It is an opportunity for personal and social development which implies being involved in diverse activities.

There is continuity in the type of activities people do before and after retirement. More than two thirds of people do not initiate new activities ,cultural, artistic or social after retiring. People starting new activities go sightseeing, do handicrafts, practice sport and go to performances. They also watch TV, go to the park and for a walk, listen to the radio, go shopping and read everyday. Fewer go to bars, associations or elderly clubs (Montero García \& Bedmar Moreno, 2010; Núbia Alvarenga et al., 2009).

\section{OBJECTIVES}

The aim of the learning partnership was "to encourage the development of innovative practices in education of older people and their transfer between countries".

\section{Specific objectives:}

- Understand the importance of social contacts, especially in old age.

- Develop internal and external independence in old age.

- Improve the quality of life and welfare. 
- Provide security and increase the autonomy of the elderly.

- Prevent and control chronic diseases.

- Conserve and restore physical, mental and social functions.

- Raise awareness of the reality of the elderly European citizens.

- Promote communication, friendship and interpersonal communication.

\section{METHODS}

The European project entitled "Integrating adults and the elderly towards a Europe of knowledge", coordinated by the University of Almería, within the actions of "Grundtvig learning partnerships for adult education" has carried out the assessment of an educational program for people over 55 years in five countries.

As a whole, each country prepared 18 training sessions (with a duration of 90 minutes each) in one or more samples of their population. This program consisted of five modules with contents on leisure and spare time, social relationships, health, new technologies and culture. Information was obtained about the population needs and the proposals that emerged during the research.

The sample in Spain consisted of 100 seniors from the province of Almería. A prerequisite was that participants should be willing to participate openly in these situations, laying aside the avoidance behaviour.

The aim of the training groups was to improve social skills such as:

- Learning to make requests appropriately, ask for information, make complaints, insist on something, ask a favour from someone, claim something for oneself or others.

- Refusing inappropriate demands or requests, learn to say no, not to try to please everyone, to respect our own needs and learn to tolerate that others may be angry about it. Not to avoid disputes because of fear of conflict, to deny any request, reject a proposal.

- Express and tolerate criticism, learn to accept public comments, learn to speak openly, without doubts, and properly.

- Analyse different examples of active lifestyle, taking into account the importance of personal well-being as useful and capable people in a society that needs solidarity and experience.

- Analyse the importance of active participation as a mechanism of protection and defense against loneliness and depression.

- The health module was developed to provide information in the specific area of health, having included a specialist like a physician or a clinical psychologist among their staff members.

- In the culture module, all the countries provided information about: flags and maps; geographical data; population; languages; history; climate; flora and fauna. The Partners of the Project made a discussion on: What do they know? What do they want to learn? Internalize know- 
ledge of each country, establish similarities and differences in cultural issues. Enjoy the cuisine of European Union member countries and present the foods that help longevity, according to the inhabitants of different countries' members.

- Get to know and experience different cultures and customs through other colleagues' experiences.

- Reflect on which of these aspects we have in common, which set us apart, and what should be incorporated or changed in order to improve our quality of life.

Step One: Motivation. We used case analysis on different ways of communication, interpersonal conclusions, proposals and personal commitment. Short stories, personal experiences and interests, audiovisual presentations, case study, etc. The teaching-units were adapted to the elderly's own interests, by expanding, adding or eliminating contents. Preparing the course, finding information, collecting material (magazines, books, Internet, etc.).

Step Two: Deepening insights into the topics. We used oral presentations of the topics, reflection and debate. A short statement with teaching aids (e.g. PowerPoint presentation, further written information given to students). The methodology should be highly participatory and active, based on previous experiences of the participants, based on their everyday reality, aiming to promote positive changes that result in improvement in their interpersonal communication and, consequently, in their quality of life. Video Forum. Group work and panel discussions. Questions/explanations. Role playing. Team work, presentation of more questions and/or of the conclusions in the class. Planning together homework and have a feedback about the applicability of the course. Practising mutual help to be more active, e.g. walking together or in little groups, exercising, healthy eating, etc.

The following teaching tools and methods were proposed as useful to promote intercultural communication skills: Simulation activities, followed by reflective discussion and/or written analysis; Informal face to face interaction in hypothetical contact situations; Guided group activities; Student diary; Questionnaires; Peer teaching; Promote contact with people from other countries; Reports; Oral presentations; Ethnographic projects.

In New Technologies module, we used participatory oral presentations, illustrated with PowerPoint files about the unit contents; small group work; active participation of students on computer skills.

Evaluation. We suggest having both an initial and a final evaluation. This evaluation is intended not to quantify how much new information and concepts our trainees might have learnt, but to get to know the grade of their satisfaction with this new information, their self-esteem increasing, the changes in their life style, the improvement in their quality of life, etc. During the final evaluation, teaching process can be also assessed. 


\section{RESULTS}

The courses provide knowledge and understanding about culture, institutions and different ways of life in diverse communities, and encourage reflection about their own cultural behaviors, practices and attitudes, as well as those of others. Old people enhance communication in their community, by means of meetings in which they talk about similar concerns. This can help the elderly to overcome problems and reduce feelings of loneliness. The courses also help old people acquire new knowledge and skills in a rapidly changing world.

In our project, the main challenges were to motivate the elderly to use adequately their free time with different leisure activities, and to give them the opportunity to develop skills to 'live the moment', according to their personalities and interests. Having good quality of life and feeling personal control represent key elements for experiencing the retirement positively.

Some of the activities put into practice within the program were as follows: Group work to rehearse social skills in certain situations, such as starting and maintaining conversations with others in different contexts; express opinions, agreement and disagreement; make and accept compliments; express love, affection and appreciation for others; show appropriate facial expressions during peer interaction in different situations; look at the speaker during interaction; show / maintain an appropriate distance / proximity with the other; smile to others in appropriate situations; adopt an appropriate voice volume during disputes.

Concerning the culture module, visits were scheduled to political parties, clubs and institutions where volunteer work was being done (e.g. childcare, hospitals, etc.).

The methodology was dynamic and open. In every session, arose really vivid discussions, showing the different perspectives within the group. During these discussions, the elderly expressed their own experiences. The participants were open towards methodology which was unfamiliar to them: working in small groups, visualizing, etc. Psychomotor exercises were developed in each session. The European diversity was included in almost all modules. Participants discussed diversities and similarities in every field, comparing and finding both positive and negative points. They expressed their needs in a group and discussed their likelihood of being fulfilled. This exchange of opinions contributed significantly to self-reflection.

This training has shown some aspects about ageing, such as the removal of the image of the idle retired person; at the same time it promotes active retirement, intergenerational relationships and independence, and improves social and personal skills.

Fears related to new technologies decreased (they lost their fear to face new technologies). They consolidated relationships. In the area of social relations, they dealt with their life and their past. They learnt to not feel guilty when making use of their time for themselves. The topic "health" was the most 
important one. They were encouraged to live in a more healthy way. They got new knowledge and experience; they realized that the university is still open for them, they can come in at any time, they are always welcome.

\section{DISCUSSION}

The perception of old people in the classroom has changed during the last decade, from focusing on welfare speech about the needs of the elderly, linked to situations of physical, economic and relational dependency, into a new approach based on entertainment, general culture and formation specialized on some issues related to new technologies, linked to an increasingly heterogeneous reality with different interests, capacities and life situations (Padilla-Góngora, Lopez-Liria, \& Martínez-Martínez, 2012).

Active social participation is an important indicator for the quality of life in adulthood, and it seems to decrease in old age. Participation in clubs, groups, initiatives, political parties and organizations of all kinds are understood as a mechanism of social integration, which is mutually related to other integration entities as family, work, neighbourhood and friends. Political participation is considered as a component of basic social integration. Participation needs social competencies, like the preparedness for cooperation, the ability for conflicts, empathy and change of perspectives (SOLIDAR European Network, 2014).

Social participation helps to integrate the elderly in society and produces many important contacts. This can prevent isolation and loneliness of the elderly and give the feeling of being needed. To be needed and to have useful activities is especially important for people after retirement, when the children have left home and in the case of loss of partner. Through active participation, either in clubs, volunteering, etc. the elderly can use their potential and experience gained during their life. This also gives them the recognition they need having lost their role as professionals in their former jobs (National Seniors Council, 2010).

Many of the once-disabling problems of ageing can be managed through improved health care and the use of assistive devices. Simple but effective changes in the home environment can be made that prevent problems and enable the older person to maintain independence. The person who has had good health habits when younger and who maintains these habits throughout life can expect to age with a sense of well-being and continued enthusiasm for living (Smith, \& Gove, 2005). A healthy lifestyle includes getting plenty of appropriate physical activity, such as simple stretches and walking. Research confirms that physical activity prevents problems as people age such as increased weight gain and risk of cardiovascular disease. Activities that increase strength and mobility can also help older adults remain independent. To stay healthy, older adults also need adequate sleep, sufficient fluid intake, nutritious foods, and a healthy and comfortable body weight (NHS England, \& Age UK, 2015). 
The mobile phone is nowadays, par excellence, the connecting link with others, becoming of special relevance to the elderly and mainly those who live alone, providing greater independence and autonomy of the user. Old people sometimes feel dependent for the maintenance and control of their information. Often this is not due to cognitive problems, but the ignorance they have in the task. Old people think it is high time to break this barrier and be updated on these changes that new technologies bring with them (SOLIDAR European Network, 2014; Zelinski, \& Reyes, 2009).

As other authors remarked previously, we conclude emphasizing how education, through leisure programs, has modified the old conception about "elderly" and this stage is defined through parameters that refer to autonomy, development, relationship, participation and creativity in old people (Montero García \& Bedmar Moreno, 2010).

\section{CONCLUSIONS}

Participants' motivation increased as the sessions were developed, since the contents of the classes agreed with their own interests, with a constant widening of knowledge. Everybody had an active role in the discussions. This training has shown some aspects about ageing, such as the removal of the image of the idle retired person; at the same time it promotes active retirement, intergenerational relationships and independence, and improves social and personal skills. Active social participation increases social contacts and prevents isolation and loneliness, enriching their lives.

All program modules were carried out. The program has been very rewarding for both participants and teaching staff. The students themselves decided which topics or aspects should be studied in depth. This educational program has improved the quality of life of the elderly by developing their potential to society. They found the program 'too short' (they asked for more sessions) and they asked for its continuation or reedition.

The main advantages about the use of the computer is the social interaction in an environment rich in sensory stimulation, in which is also possible to promote an increasingly more technical approach. All these aspects have to contribute to fostering a quality old age.

The results can be adapted to other regions of Spain. The elderly community would benefit enormously from them. The curriculum can be used by others, which should be experienced and flexible to adapt it to the needs and wishes of their own groups. We propose to implement the CHANCE curriculum into other courses on both regional and national levels. 


\section{REFERENCES}

[1] Diener, E., \& Suh, E. M. (2000). Self, Hyphen between Culture and Subjective Well-being. In: E. Diener, \& E, M \& Suh (Eds.) Culture and Subjective Well-Being (pp. 63-86). Cambridge: MIT Press.

[2] Dolan, P., Peasgood, T., \& White, M. (2008). Do we really know what makes us happy? A review of the economic literature on the factors associated with subjective well-being. Journal of Economic Psychology, 29(1), 94-122. http://doi.org/10.1016/j.joep.2007.09.001

[3] File, T., \& Ryan, C. (2014). Computer and Internet use in the United States. American Community Survey Reports, November, 16. Retrieved from http:/ / www.census.gov/prod/2013pubs/ p20-569.pdf

[4] Gagné, M., \& Deci, E. (2005). Self-determination theory and work motivation. Journal of Organizational Behavior, 26(4), 331-362. http://doi.org/10.1002/job.322

[5] Garssen, J. (2006). Will life expectancy continue to increase or level off ? Weighing the arguments of. Centraal Bureau Voor de Statistiek, Retrieved from http://www.cbs.nl/nr/ rdonlyres/2a48dc16-2062-4116-97f7-63ec41ef5d69/0/2006willifeexpectancycontinueart.pdf

[6] Helliwell, J. F., \& Putnam, R. D. (2004). The social context of well-being. Philosophical Transactions of the Royal Society of London. Series B, Biological Sciences, 359 (1449), 1435-1446. http:/ / doi.org/10.1098/rstb.2004.1522.

[7] Independent Age. (2008). Older people, technology and community. Calouste Gulbenkian Foundation, 1-37. Retrieved from http://www.gulbenkian.org.uk/pdffiles/Older-people-technology-and-community.pdf

[8] López-Liria, R., Padilla-Góngora, D., Catalan-Matamoros, D., Rocamora-Pérez, P., Pérez-de la Cruz, S., \& Fernández-Sánchez, M. (2015). Home-Based versus Hospital-Based Rehabilitation Program after Total Knee Replacement. BioMed Research International, 1-9. http://doi. org/10.1155/2015/450421

[9] Montero García, I., \& Bedmar Moreno, M. (2010). Ocio, tiempo libre y voluntariado en personas mayores. Polis: Revista Latinoamericana, (26), 3. Retrieved from http:/ / dialnet.unirioja.es/ servlet/articulo?codigo $=3259584 \&$ info $=$ resumen\&idioma $=$ POR

[10] National Seniors Council. (2010). Report of the National Seniors Council on Volunteering Among Seniors and Positive and Active Aging. Retrieved from http://www.seniorscouncil.gc.ca/eng/ research_publications/volunteering.pdf

[11] Nolte, E. E., \& McKee, M. (2008). Caring for people with chronic conditions: a health system perspective. European Observatory on Health Systems and Policies Series, XXI, 259 Retrieved from

[12] http://www.euro.who.int/_data/assets/pdf_file/0006/96468/E91878.pdf

[13] Núbia Alvarenga, L., Kiyan, L., Bitencourt, B., \& da Silva Wanderley, K. (2009). The impact of retirement on the quality of life of the elderly. Rev Esc Enferm USP, 43(434), 794-800. http:// doi.org/10.1590/S0080-62342009000400009

[14] Padilla-Góngora, D, Lopez-Liria R, Martínez-Martínez, A., \& Soro G. (2012). Diseño y experimentacion de un programa educativo para mayores en Almería: proyecto Grundtvig. International Journal of Developmental and Educational Psychology, 3, 309-315.

[15] SAMHSA. (2000). Substance Abuse Among Older Adults. Substance Abuse Among Older Adults, 26, 152.

[16] Smith, S., \& Gove, J. E. (2005). Physical Changes of Aging. Aging, 1-7. Retrieved from https:/ / edis.ifas.ufl.edu/pdffiles/HE/HE01900.pdf

[17] SOLIDAR European Network. (2014). Briefing building inclusive learning societies: active ageing and solidarity between generations, 1-3. Retrieved from http://www.solidar.org/IMG/pdf/ solidar-active_ageing_and_intergenerational_solidarity.pdf

[18] United Nations, Department of Economic and Social Affairs, P. D. (2013). World Population Ageing. United Nations, 114. http:// doi.org/ST/ESA/SER.A/348

[19] Zelinski, E. M., \& Reyes, R. (2009). Cognitive benefits of computer games for older adults. Gerontechnology: International Journal on the Fundamental Aspects of Technology to Serve the Ageing Society, 8(4), 220-235. http://doi.org/10.4017/gt.2009.08.04.004.00 